\title{
A new approach towards thieno[2,3-h][1,6]naphthyridines
}

\section{Maria P. Goykalova (Averyasova)1, Victor V. Dotsenko1,2*, Elena A. Chigorina ${ }^{3}$, Nikolay A. Aksenov ${ }^{4}$, Inna V. Aksenova ${ }^{4}$, Vladimir D. Strelkov ${ }^{1,5}$}

${ }^{1}$ Kuban State University, 149 Stavropolskaya str, Krasnodar, 350040 Russia e-mail: victor_dotsenko@bigmir.net

${ }^{2}$ ChemEx Lab, Vladimir Dal' Lugansk National University, 20A/7 Molodezhny, Lugansk, 91034 Russia

${ }^{3}$ The Federal State Unitary Enterprise «Institute of Chemical Reagents and High Purity Chemical Substances of National Research Centre «Kurchatov Institute», 3 Bogorodsky val, Moscow, 107076 Russia

${ }^{4}$ Department of Chemistry, North Caucasus Federal University, 1a Pushkin St., 355009 Stavropol, Russia

${ }^{5}$ All-Russian Research Institute of Biological Plant Protection, Laboratory of plant growth regulators, 350039 Krasnodar, Russia

\begin{abstract}
Triethylammonium salts of (4-aryl-3-cyano-6-oxo-1,4,5,6-tetrahydropyridin2-yl)malononitriles were prepared by reaction of aldehydes with Meldrum's acid and 2-amino-1,1,3-tricyanopropene (malononitrile dimer) in the presence of triethylamine. Upon treatment with alpha-mercaptocarbonyl compounds in the presence of alkali, new thieno[2,3-h][1,6]naphthyridines were prepared in good yields.
\end{abstract}

\section{Keywords}

Meldrum's acid, 2-amino-1,1,3-tricyanopropene, malononitrile dimer, thieno[2,3-h][1,6]naphthyridines

(3-Cyanopyridin-2(1H)-ylidene)malononitriles $\mathbf{1}$ have been recognized as convenient reagents for various cascade transformations and are quite often used for the synthesis of heterocyclic compounds, especially 1,6naphthyridines. (3-Cyanopyridin-2(1H)-ylidene)malononitriles $\mathbf{1}$ can be easily prepared by reaction of various 1,3-biselectrophilic reagents with 2aminoprop-1-ene-1,1,3-tricarbonitrile (malononitrile dimer) (the chemistry 
of 2-aminoprop-1-ene-1,1,3-tricarbonitrile has been covered in reviews [13]).<smiles>[R]C([R])C([R])[R][H]</smiles>

While continuing research in the chemistry of malononitrile dimer, we decided to study the reactivity of malononitrile dimer with 5-arylmethylene 2,2-dimethyl-1,3-dioxane-4,6-diones 2, generated in situ from aldehydes and Meldrum's acid. We found that the reaction easily proceeds in the presence of $\mathrm{Et}_{3} \mathrm{~N}$ in boiling EtOH to give dicyanomethylide salts 3, or, after treatment with an acid - corresponding piperidines 4:<smiles>CCOCCN(C)CCO</smiles>

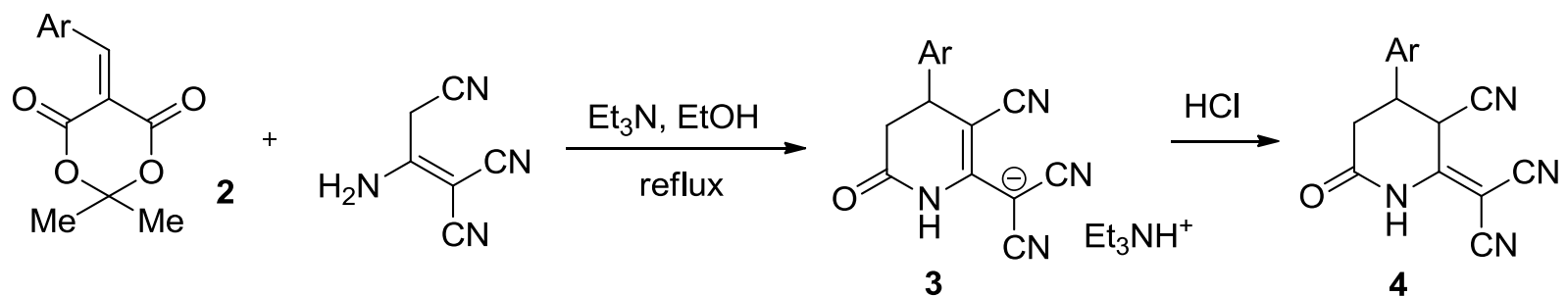

The structures of compounds $\mathbf{3}$ and $\mathbf{4}$ were studied by IR spectroscopy, ${ }^{1} \mathrm{H}$ and ${ }^{13} \mathrm{C}$ NMR spectroscopy, mass spectrometry, HPLC-MS and elemental analysis. Noteworthy that preparation of analogs of compounds $\mathbf{4}$ was reported before [4], though by a quite different method. The reaction of (3-cyanopiperidin-2ylidene)malononitriles 4 or salts $\mathbf{3}$ with thioglycolic acid anilides in hot $\mathrm{EtOH}$ in the presence of an excess of $\mathrm{Et}_{3} \mathrm{~N}$ proceeded through an attack by ArNHC(O) $\mathrm{CH}_{2} \mathrm{~S}^{-}$anion at one of the nitrile groups of the $=\mathrm{C}(\mathrm{CN})_{2}$ moiety. The products were identified as a mixture of 1,6-naphthyridines 5 and their Thorpe-Ziegler cyclization products, isomeric thieno[2,3h] [1,6]naphthyridines 6 . 


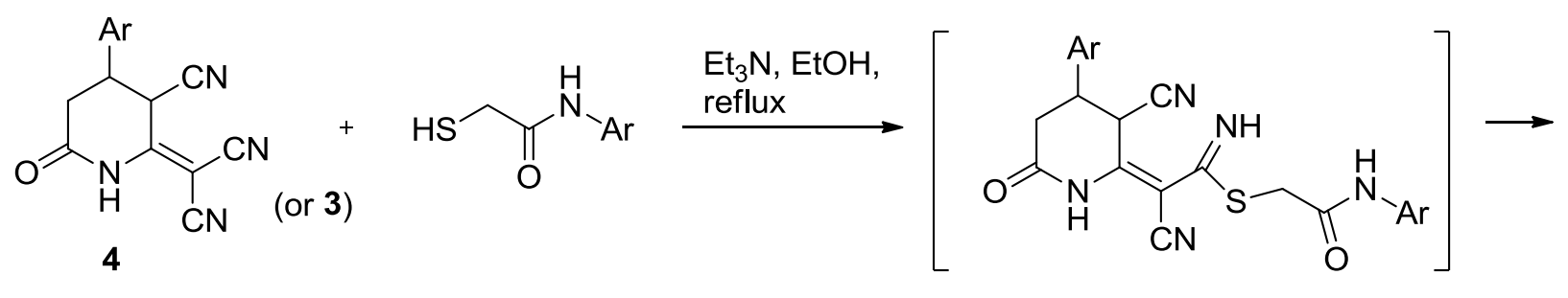<smiles>N#Cc1c(SCC(=O)NBr)nc(N)c2c1NC(=O)CC2Br</smiles><smiles></smiles>

When $\mathrm{KOH}$ was taken instead an organic base, the yields of thieno[2,3$\mathrm{h}][1,6]$ naphthyridines were increased up to $84 \%$ to give only 6 in pure form. In addition, when the mixtures $\mathbf{5 + 6}$ were treated with an excess of $10 \%$ aq. $\mathrm{KOH}$, thieno[2,3-h][1,6]naphthyridines 6 were obtained in quantitative yields.<smiles>C/C(C#N)=C1/NC(=O)CC(Br)C1C#N</smiles>

Experimental

Preparation of (4-aryl-3-cyano-6-oxo-1,4,5,6-tetrahydropyridin-2yl)malononitrile triethylammonium salts 3 and (4-aryl-3-cyano-6-oxopiperidin2-ylidene)malononitriles 4 (General method).

A 250-ml round bottom flask was charged with Meldrum's acid (6.0 g, 41.6 mmol), EtOH ( $50 \mathrm{ml})$, aromatic aldehyde $(42 \mathrm{mmol})$, and 6 drops of $\mathrm{Et}_{3} \mathrm{~N}$. The mixture was stirred until complete dissolution of the starting reagents (5-10 min). Precipitation of condensation product (5-arylmethylene 2,2-dimethyl1,3-dioxane-4,6-diones 2) may occur during this time. The mixture was treated with additional EtOH $(20 \mathrm{ml})$, malononitrile dimer 3 (5.5 g, 41.6 mmol), and $\mathrm{Et}_{3} \mathrm{~N}$ (8.7 ml, $62.4 \mathrm{mmol}, 1.5$ equiv). The obtained solution was refluxed for 1-3 $\mathrm{h}$, evaporated to a syrup consistency, cooled, treated with acetone $(20 \mathrm{ml})$ and EtOH $(5 \mathrm{ml})$. The crystalline precipitate of salt $\mathbf{3}$ was filtered off after $48 \mathrm{~h}$, washed with cold acetone and petroleum ether. The filtrate obtained after separation of the salt was vigorously stirred and cooled while adding a mixture of alcohol and concd. $\mathrm{HCl}$ to $\mathrm{pH} 2$. The yellow 
precipitated product was filtered off after $4 \mathrm{~h}$, washed with EtOH and petroleum ether, to give compounds 4 . When no formation of salts $\mathbf{3}$ was observed, the obtained acetone-alcohol solution was treated by dropwise addition of an excess of 1:1 concd. $\mathrm{HCl}$ solution in $\mathrm{EtOH}$ to $\mathrm{pH} 2$. The obtained suspension was stirred for 3-4 h, the product was filtered off, washed with EtOH and petroleum ether, giving compounds 4.

Synthesis of thieno[2,3-h][1,6]naphthyridines 6

A mixture of trinitriles $4(1.90 \mathrm{mmol})$ or salts $3(1.90 \mathrm{mmol})$ and thioglycolic acid anilides (1.90-2.00 mmol) in $96 \% \mathrm{EtOH}(10 \mathrm{ml})$ was treated with an excess of $10 \%$ aqueous $\mathrm{KOH}$ solution $(1.0 \mathrm{ml}, 1.95 \mathrm{mmol}, \sim 1.5$ equiv). The obtained yellow solution was stirred and refluxed for 3-5 h. The mixture was treated with excess of $\mathrm{AcOH}$, maintained for $24 \mathrm{~h}$, the precipitate was filtered off and washed with EtOH. The reaction products were purified by refluxing with $\mathrm{AcOH}$, cooled, the precipitate was filtered off and dried at $100^{\circ} \mathrm{C}$. Thienonaphthyridines $\mathbf{6}$ were obtained as beige or yellow powders.

5,9-Diamino-2-oxo-N,4-diphenyl-1,2,3,4-tetrahydrothieno[2,3h][1,6]naphthyridine-8-carboxamide.

Yield $75 \%$, beige powder, decomp. temp. $>300{ }^{\circ} \mathrm{C}$. IR spectrum, $v, \mathrm{~cm}^{-1}: 3311$, $3151(\mathrm{~N}-\mathrm{H}), 1695(\mathrm{C}=0) .{ }^{1} \mathrm{H}$ NMR spectrum (400 MHz, DMSO-d 6 ), $\delta, \mathrm{ppm}(\mathrm{J}$, $\mathrm{Hz}$ ): $2.76\left(1 \mathrm{H}\right.$, br. d (unresolved dd), $\left.{ }^{2} \mathrm{~J}=15.7,3-\mathrm{CH}(\mathrm{cis})\right) ; 3.21\left(1 \mathrm{H}, \mathrm{dd},{ }^{2} \mathrm{~J}=\right.$ $15.7,{ }^{3} \mathrm{~J}=6.7,3-\mathrm{CH}$ (trans)); 4.60-4.61 (1H, m, 4-CH); 7.04-7.08 (1H, m, H Ph); 7.20-7.32 (7H, m, H Ph); 7.68 (2H, d, 3J = 8.1, H Ph); 9.64 (1H, br. s, NH); 10.01 $(1 \mathrm{H}$, very br. $\mathrm{s}, \mathrm{NH})$. The signals of $5-\mathrm{NH}_{2}$ and $9-\mathrm{NH}_{2}$ amino groups were observed as a very broad peak at $7.20-8.70 \mathrm{ppm}$, probably due to partial protonation after treatment with $\mathrm{AcOH} .{ }^{13} \mathrm{C}$ NMR spectrum $(100 \mathrm{MHz}$, DMSOd6), $\delta$, ppm: 34.0 (C-3); 37.8 (C-4); 97.0 (C-4a); 101.3 (C-Ar); 108.7 (C-Ar); 120.2 (C Ph); 123.5 (C Ph); 127.1 (C Ph); 127.2 (C Ph); 128.4 (C Ph); 128.7 (C $\mathrm{Ph}$ ); 138.8 (C-1 Ph); 139.3 (C-1 Ph); 145.2 (C Ar); 148.1 (C Ar); 150.1 (C Ar); 153.9 (C Ar); 163.4 (CONH); 169.0 (CONH). ${ }^{13} \mathrm{C}$ NMR DEPT-135 spectrum $(100$ MHz, DMSO-d6), $\delta$, ppm: 33.8 (C-4); 37.5 (C-3); 121.0 (CH Ph); 123.2 (CH Ph); 126.8 (CH Ph); 127.0 (CH Ph); 128.1 (CH Ph); 128.4 (CH Ph).

${ }^{1} \mathrm{H}$ and ${ }^{13} \mathrm{C}$ NMR spectra of 5,9-diamino-2-oxo-N,4-diphenyl-1,2,3,4tetrahydrothieno[2,3-h][1,6]naphthyridine-8-carboxamide are shown in the Figures 1-3. 


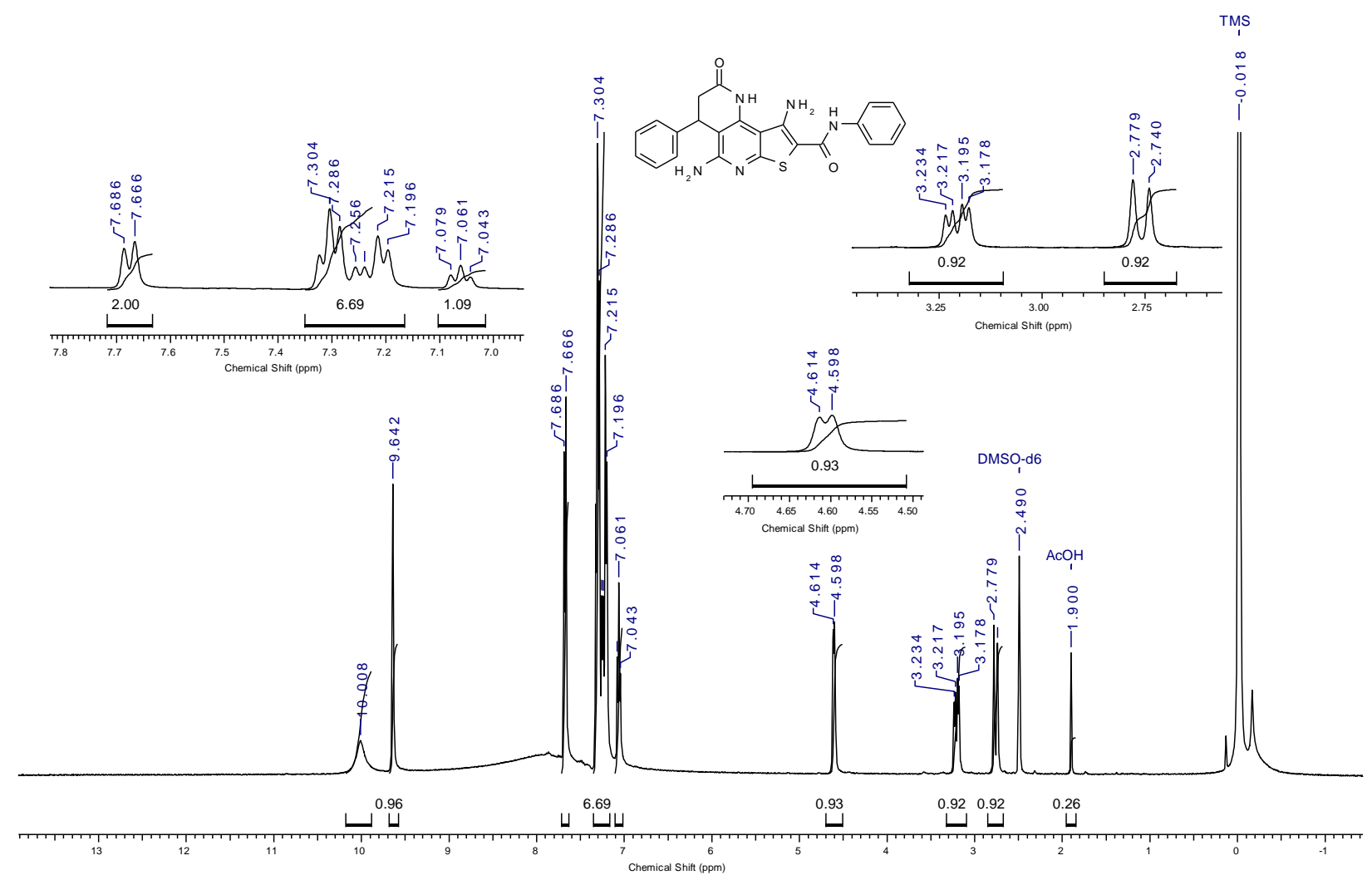

Fig. 1. ${ }^{1} \mathrm{H}$ NMR spectrum (400 MHz) of 5,9-diamino-2-oxo-N,4-diphenyl1,2,3,4-tetrahydrothieno[2,3-h][1,6]naphthyridine-8-carboxamide
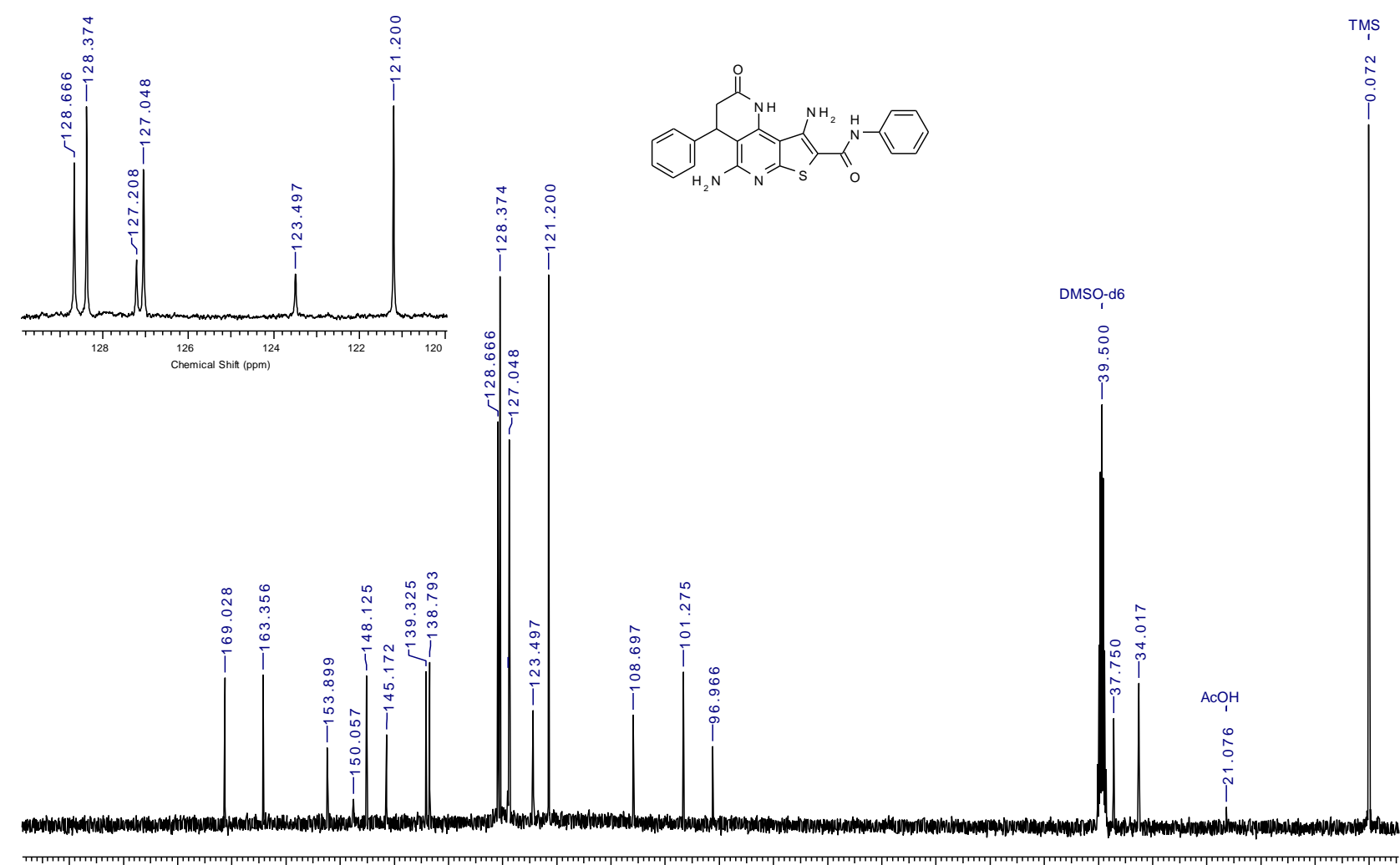

Fig. 2. ${ }^{13} \mathrm{C}$ NMR spectrum (101 MHz) of 5,9-diamino-2-oxo-N,4-diphenyl1,2,3,4-tetrahydrothieno[2,3-h][1,6]naphthyridine-8-carboxamide 


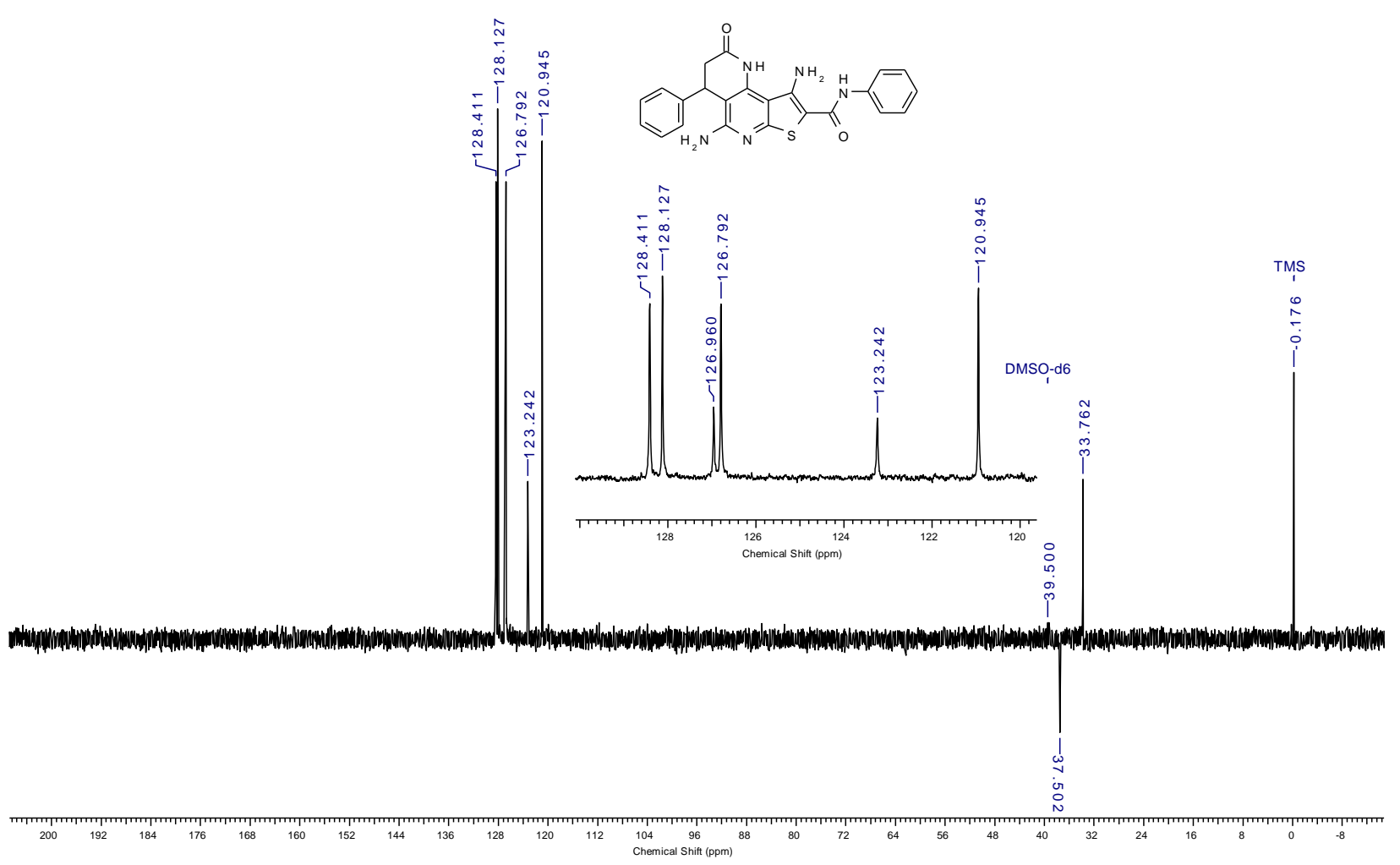

Fig. 3. ${ }^{13} \mathrm{C}$ NMR DEPT-135 spectrum (101 MHz) of 5,9-diamino-2-oxo-N,4diphenyl-1,2,3,4-tetrahydrothieno[2,3-h][1,6]naphthyridine-8-carboxamide

\section{References}

1. Freeman, F. // Chem. Rev. 1969, 69, 591.

2. Fatiadi, A. J. // Synthesis 1978, 165.

3. Sharanin, Yu. A.; Promonenkov, V. K.; Litvinov, V. P. in Results of Science and Technology. Organic Chemistry, Shvekhgeimer, M.-G. A., Ed.; VINITI: Moscow, 1991, Vol. 20 (Part 2), p. 59 (in Russian).

4. Victory, P. J.; Teixidó, J.; Borrell, J. I. // Heterocycles 1992, 34, 1905. 